\title{
Corticotropin-Releasing Hormone Deficiency
}

National Cancer Institute

\section{Source}

National Cancer Institute. Corticotropin-Releasing Hormone Deficiency. NCI Thesaurus.

Code C127157.

Diminished production of adrenocortical hormones due to presumed insufficient secretion of corticotropin-releasing hormone from the hypothalamus. 